\title{
A (DES)ORDEM DA IMAGEM NA COMUNICAÇÃO POLÍTICA BRASILEIRA: POSSIBILIDADES ANALÍTICAS A PARTIR DA NOÇÃO DISCURSIVA DE RELAÇÕES INTERCENOGRÁFICAS
}

\author{
Roberto Leiser Baronas* \\ Universidade Federal de São Carlos \\ Departamento de Letras \\ São Carlos, SP, Brasil
}

\begin{abstract}
Resumo: Neste ensaio, postula-se que a imagem enquanto "um operador da memória social no seio de nossa cultura", como qualquer outro discurso, é engendrada tanto por uma ordem quanto por uma desordem discursiva e que essas (des)ordens discursivas ocorrem em cenas genéricas bastante marcadas institucionalmente. Assumindo, então, o postulado de que diferentes (des)ordens discursivas engendram não só o verbal, mas também a imagem, a questão específica neste artigo é como podemos apreender discursivamente essa (des)ordem da imagem na comunicação política digital. Que ferramentas conceituais poderíamos mobilizar para entender a (des)ordem da imagem na comunicação política? O texto ancora-se teórico-metodologicamente nas proposições de Dominique Maingueneau (2006 e 2013b), à luz da tríade conceitual cena englobante, cena genérica e cenografia, fazendo esta última noção ranger, enquanto relação discursiva intercenográfica, e mobiliza um pequeno conjunto de imagens, mais especificamente fotografias, que circularam na mídia digital e nas redes socais brasileiras entre os anos de 2011 e 2015, enquanto comunicação política, sobre o ator político Dilma Rousseff.
\end{abstract}

Palavras-chave: Discurso. Imagem. Cena da enunciação. Relações intercenográficas.

1 POUCAS PALAVRAS INICIAIS

Michel Foucault, em $A$ ordem do discurso, texto-programa de uma aula magna ${ }^{1}$, proferida por ocasião de sua nomeação ao Collège de France, em 2 de dezembro de 1970, propõe que em toda sociedade a produção dos mais variados tipos de discurso "é ao mesmo tempo controlada, selecionada, organizada e redistribuída por certo número de procedimentos que tem por função conjurar seus poderes e perigos, dominar seu acontecimento aleatório, esquivar sua pesada e temível materialidade" $(1999$, p.10).

\footnotetext{
* Doutor em Linguística e Língua Portuguesa pela FCL/UNESP - Câmpus de Araraquara; professor associado no Departamento de Letras da UFSCar e pesquisador do $\mathrm{CNPq}$, nível 02. E-mail: baronas@uol.com.br.

${ }^{1}$ Nessa aula magna, seguindo os princípios de rarefação dos discursos e tendo tais princípios como uma espécie de horizonte para futuros programas de pesquisa, Foucault propõe analisar os discursos a partir de dois conjuntos. "De uma parte o conjunto 'crítico', que põe em prática o princípio da inversão: procurar cercar as formas da exclusão, da limitação, da apropriação [dos discursos]; mostrando como se formaram, para responder a que necessidades, como se modificaram e se deslocaram, que força exerceram efetivamente, em que medida foram contornadas. De outra parte, o conjunto 'genealógico' que põe em prática os três outros princípios: como se formaram, através, apesar, ou com apoio desses sistemas de coerção, séries de discursos; qual foi a norma específica de cada uma e quais foram suas condições de aparição, crescimento, de variação.” (1999, p. 22).
} 
Nesse texto-aula, Foucault assevera existência de diversos sistemas de exclusão que atingem radicalmente os discursos. Alguns desses procedimentos são de natureza externa: a palavra proibida; a segregação da loucura e a vontade de verdade. Estes sistemas de exclusão externa opõem em um jogo incessante o poder e o desejo. Os outros procedimentos são de natureza mais interna, visto que são os próprios discursos que exercem seu próprio (auto)controle, funcionando a "título de classificação, de ordenação, de distribuição, como se se tratasse, desta vez, de submeter outra dimensão do discurso: a do acontecimento e o do acaso" (1999, p.11). Dentre os procedimentos internos de exclusão dos discursos estão o comentário; a disciplina e o autor.

O filósofo francês crê, ainda, na existência de "um terceiro grupo de procedimentos que permitem o controle dos discursos. Nesse caso, não se trata de dominar os poderes que tais discursos têm, nem de conjurar os acasos de sua aparição; trata-se de determinar as condições de seu funcionamento" (p.12), impondo aos indivíduos, que pronunciam os discursos, a inscrição em determinadas regras, de maneira a não permitir que todos possam livremente acessar esses discursos. Trata-se no entendimento de Foucault da rarefação dos sujeitos que falam, uma vez que "ninguém entrará na ordem do discurso se não satisfizer a certas exigências ou se não for, de início, qualificado para fazê-lo" (p. 32). O princípio de rarefação dos sujeitos autorizados a falar tem a ver, segundo Foucault, com o fato de que "nem todas as regiões do discurso são igualmente abertas e penetráveis; algumas são altamente proibidas [...], enquanto outras parecem quase abertas a todos os ventos e postas, sem restrição prévia, à disposição de cada sujeito que fala" (p. 33).

A hipótese de trabalho perscrutada por Michel Foucault sobre a existência de uma ordem, que rareia os discursos, impossibilitando o seu acontecimento aleatório, embora epistemologicamente pertinente, sobretudo do ponto de vista da produção desses discursos, apresenta, em nosso entendimento, pelo menos duas lacunas: primeira, Foucault não se preocupa com a circulação dos discursos e, na esteira dessa lacuna, nem com que tipos de discurso podem circular, e, segunda, Foucault só se debruça sobre os sujeitos jurídicos. Os menos marcados institucionalmente são deixados de fora de sua problemática. Entendemos que essas eventuais lacunas têm a ver com as condições históricas de possibilidade do texto de Michel Foucault: os anos 1970 do século passado; a cena genérica aula inaugural; a inexistência à época de dispositivos sociotécnicos de comunicação como a web.

Uma possível resposta para tais lacunas pode ser buscada em um trabalho do próprio Michel Foucault, talvez o menos solene de seus ditos e escritos. Trata-se do livro $^{2}$ Eu, Pierre Rivière, que degolei minha mãe, minha irmã e meu irmão: um caso de parricídio do século XIX, publicado em 1981. Este livro, um dossiê, produzido a várias mãos e organizado por Michel Foucault, busca compreender as relações entre a psiquiatria e a justiça penal. Essa obra coletiva toma como objeto de reflexão o caso Rivière, publicado na França nos Annales d'hygiène publique et de médicine légale de

\footnotetext{
${ }^{2}$ Essa obra é resultado de um trabalho coletivo desenvolvido em um seminário no Collège de France no início dos anos oitenta do século passado. Seus autores são Blandine Barret-Kriegel, Gilbert BurletTorvic, Robert Castel, Jeanne Favret, Alexandre Fontana, Georgette Legeé, Patricie Moulin, Jean-Pierre Peter, Philippe Riot e Maryvonne Saison.
} 
1836. Diferentemente dos dossiês publicados nos Annales da época, o caso Rivière apresenta certo número de elementos extraordinários, pois em um mesmo documento estão diferentes conjuntos de textos: três relatórios médicos; um conjunto de peças judiciais e um memorial de autoria do próprio Pierre Rivière. Sobre o dossiê nos diz Foucault (1981, p. 12):

\begin{abstract}
Todos falam ou parecem falar da mesma coisa: pelo menos é ao acontecimento de 03 de junho que se referem todos os discursos. Mas todos eles, e em sua heterogeneidade, não formam nem uma obra e nem um texto, mas uma luta singular, um confronto, uma relação de poder, uma batalha de discursos e através de discursos. E ainda dizer uma batalha não é dizer o bastante; vários combates desenrolaram-se ao mesmo tempo e entrecruzando-se: os médicos tinham a sua batalha [...]; os magistrados tinham a sua batalha a respeito das perícias médicas [e o próprio Rivière tinha a sua batalha contra os médicos e os magistrados] "com seu relato preparado de antemão e para dar lugar a seu crime; suas explicações orais para fazer crer na sua loucura; seu texto escrito para fazer dissipar essa mentira, dar explicações e chamar a morte..."
\end{abstract}

Com a análise desses diferentes tipos de documentos em confronto, Foucault evidencia que é possível descrever e interpretar de algum modo o plano dessas lutas diversas, restituindo esses confrontos e essas batalhas, reencontrando o jogo desses discursos, como armas, como instrumentos de ataque e de defesa em relações de poder e saber. Em suma, Foucault nos ensina que é possível observar e descrever um conjunto de regularidades discursivas mesmo na heterogeneidade dos discursos. No entanto, apesar de Foucault nos mostrar que é possível decifrar as relações de poder, de dominação e de luta dentro das quais os discursos se estabelecem e funcionam, entendemos que este autor, por conta mesmo das condições de aparição de seu texto sobre Pierre Rivière, não toca profundamente na questão da (des)ordem dos discursos.

Seria possível, então, tomar essa lacuna nos escritos foucaultianos e transformá-la em uma questão pertinente para os estudos discursivos na atualidade? Ainda mais se levarmos em consideração o fato de que vivemos atualmente em uma sociedade em que a tecnologização dos discursos ${ }^{3}$ se faz presente de maneira tão imperiosa e consequentemente tão (des)ordenadora dos discursos que põe a circular.

Entendemos que essa questão foi parcialmente tratada no Colóquio "Análise dos discursos fora das normas: aproximações, conceitos e métodos ${ }^{4}$ ", que se realizou na Universidade de Sherbrooke, na Província do Québec, no Canadá, em junho de 2015. Como o próprio título do colóquio indicava, o objetivo do evento foi o de refletir sobre os discursos fora das normas. Ou seja, dar conta epistemologicamente e metodologicamente de discursos que, pelo seu funcionamento menos estabilizado na nossa sociedade, se apresentam menos suscetíveis, por exemplo, à ordem linguística, genérica e/ou institucional. São discursos que, para além e aquém das instituições e dos

\footnotetext{
3 Expressão tomada de empréstimo a Fairclough (1992), que designa um conjunto de técnicas de processamento dos signos, cujo objetivo precípuo é aumentar a eficácia dos discursos. Essas técnicas potencializadas com o advento da web analisam a comunicação interna e externa das empresas, incluindo também dados sobre os indivíduos comuns.

4 Colloque International Analyse des Discours Hors-Normes: approches, concepts et méthodes $<$ http://www.hors-normes2015.evenement.usherbrooke.ca/appel.html $>$.
} 
gêneros nos quais se inscrevem, arriscam a burlar o léxico, a entortar a sintaxe, a brincar com os sentidos, a enfim "profanar" as normas linguísticas, genéricas e/ou institucionais. O evento de Sherbrooke, no entanto, embora tenha avançado em relação à problemática dos discursos fora das normas, deixou de lado a possibilidade de pensar, por exemplo, em que medida diferentes textos, marcadamente os imagéticos e, sobretudo, os que circulam em diferentes dispositivos midiáticos, portanto marcados institucionalmente, também podem ser enquadrados como fora das normas.

Neste ensaio, relativamente na demão da temática desse Colóquio de Sherbrookee e um pouco na contramão de Michel Foucault, temos como questão mais ampla postular que a imagem, para além e aquém de se constituir enquanto "um operador da memória social no seio de nossa cultura", é engendrada tanto por uma ordem quanto por uma desordem discursiva, e que essas (des)ordens discursivas se dão em gêneros bastante marcados institucionalmente, como é o caso da literatura de Guimarães Rosa e de Manoel de Barros; das músicas do grupo Mamonas Assassinas; das animações computadorizadas de Shrek; do semanário humorístico francês Charlie Hebdo ou dos vídeos divulgados na web com decapitações de prisioneiros feitas pelo Estado Islâmico, ou até mesmo da comunicação política brasileira. Assumindo então o postulado de que diferentes (des)ordens discursivas engendram não só o verbal, mas também a imagem, nossa questão específica neste texto é: como podemos apreender discursivamente essa (des)ordem da imagem na comunicação política? Que ferramentas conceituais teríamos de mobilizar para dar conta da (des)ordem da imagem da cena genérica comunicação política? Ancoramo-nos teórico-metodologicamente nas proposições de Dominique Maingueneau (2006 e 2013b) à luz da tríade conceitual cena englobante, cena genérica e cenografia, fazendo esta última noção ranger, enquanto relação intercenográfica, e mobilizamos um pequeno conjunto de imagens, mais especificamente fotografias, que circularam na mídia digital brasileira e nas redes sociais, enquanto comunicação política, entre os anos de 2011 a 2015, sobre o ator político Dilma Rousseff.

\section{UM POUCO SOBRE OS FATOS DISCURSIVOS}

Nosso pequeno corpus foi extraído de diferentes plataformas discursivas: duas imagens retiradas de jornal de grande circulação nacional; uma de um site de notícias e de entretenimento e outra das redes sociais, e faz referência ao ator político Dilma Rousseff. Todas as imagens elencadas colocam cenograficamente (por ilusão de ótica ou de fotomontagem derrisória) o ator político Dilma Rousseff numa condição extremamente desfavorável: as primeiras colocam a presidente sendo atravessada por uma espada e na mira de um canhão de um tanque de guerra; a terceira em situação de angústia e desespero, e a quarta constrói cenograficamente a imagem de que a presidente está sendo penetrada sexualmente por uma mangueira de uma bomba de

\footnotetext{
${ }^{5}$ Segundo Jean Davallon (1999, p. 23), "se a imagem define posições de leitor abstrato que o espectador concreto é convidado a vir a ocupar a fim de poder dar sentido ao que ele tem sob os olhos, isso vai permitir criar, de uma certa maneira, uma comunidade, um acordo - de olhares: tudo se passa como se a imagem colocasse no horizonte de sua percepção a presença de outros espectadores possíveis tendo o mesmo ponto de vista".
} 
gasolina. Cada imagem procura, a seu modo, refratar os diferentes momentos de tensão política: pressão do PMDB por mais cargos no governo; denúncias de corrupção na Petrobrás; possibilidade de impeachment; protestos contra o aumento dos combustíveis, pelos quais o governo Dilma vem passando desde a posse de seu primeiro mandato em 2011.

A primeira imagem que frequentamos analiticamente foi publicada no Jornal $O$ Estado de S. Paulo, na edição de 21 de agosto de 2011. A cerimônia onde estava a presidente no momento do registro foi a entrega de espadins a 441 cadetes na Academia Militar das Agulhas Negras, em Resende, interior do Rio de Janeiro. Essa fotografia foi publicada na página A 7, caderno de política do Estadão, e acompanha uma reportagem, cujo título é "Desconfiado de Dilma, PMDB faz planos para 2014".

Figura 1 - 0 Estado de S.Paulo, Caderno de Política, 21/08/2011

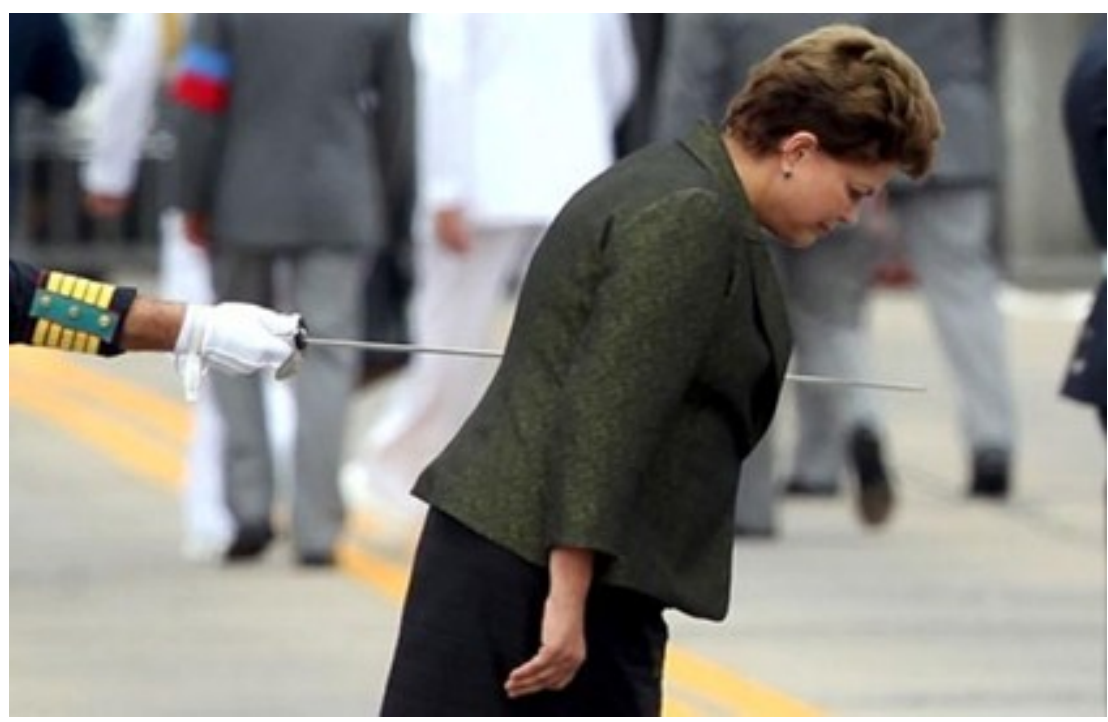

Fonte: Wilson de Sousa Júnior, Agência Estado.

A fotografia é de autoria do fotógrafo Wilton de Sousa Júnior, da Agência Estado, e ganhou, entre outros, o Prêmio Esso, na categoria fotografia, e o Prêmio Internacional de Jornalismo Rei da Espanha como melhor fotografia.

A segunda imagem que mobilizamos foi publicada no Jornal Correio Braziliense em 8 de setembro de 2014, e é de autoria de Daniel Ferreira. A fotografia registra a presença da presidente Dilma Rousseff, do vice-presidente Michel Temer, de ministros de estado e de assessores, durante desfile militar realizado em 7 de setembro último em Brasília. Junto à fotografia, que faz parte da capa do Correio Braziliense, está a chamada "Políticos denunciados fogem do 7 de setembro". 
Figura 2 - Correio Braziliense, Manchete de Capa, 08/09/2014

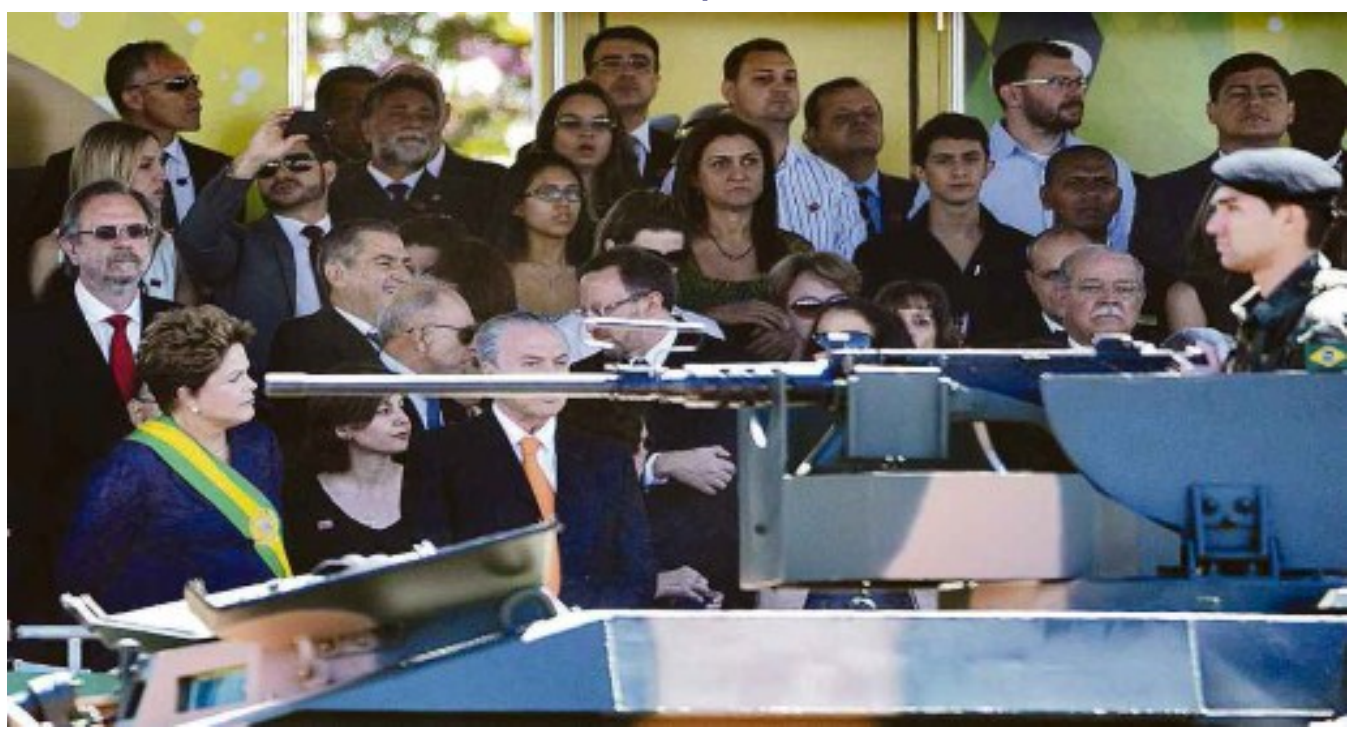

Fonte: Daniel Ferreira, Correio Braziliense.

A terceira imagem, divulgada inicialmente pela Agência de Notícias Reuters, foi publicada como página inicial no site da MSN - Brasil em 16 de março de 2015, e faz referência a uma reportagem sobre as manifestações pelo impeachment da presidente realizadas em todo o Brasil no dia 15 de março de 2015.

Figura 3 - MSN - Brasil, Página Inicial, 16/03/2015

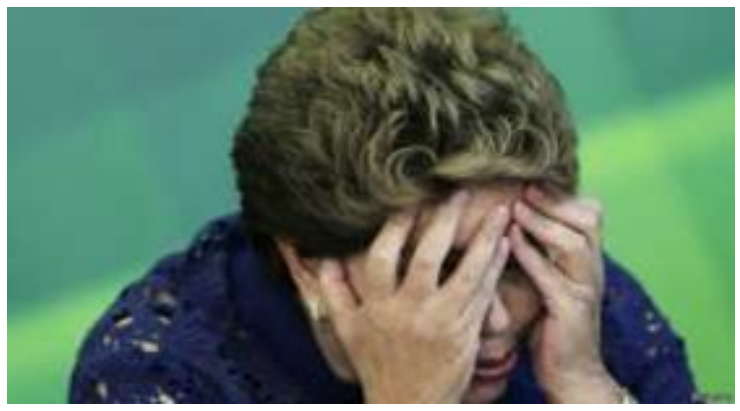

Fonte: Agência de Notícias Reuters.

A quarta imagem se constitui num adesivo misógino, que circula peles redes sociais, com base em montagens feitas ora com o rosto da presidente Dilma Rousseff, ora com o seu busto. Nesta fotomontagem, construída a partir da junção da fotografia da então candidata Dilma Rousseff a presidente nas eleições de 2014, com a fotografia das pernas abertas de uma mulher, a atual presidente aparece numa posição em que está prestes a ser penetrada sexualmente. Esses adesivos com essa imagem, antes de circularem pelas redes sociais, foram inicialmente colados na entrada do tanque de gasolina dos carros, de maneira que, quando abastecidos, passam a ideia de que a mangueira de uma bomba de gasolina está penetrando sexualmente a figura da presidente. 
Figura 4 - Fotomontagem
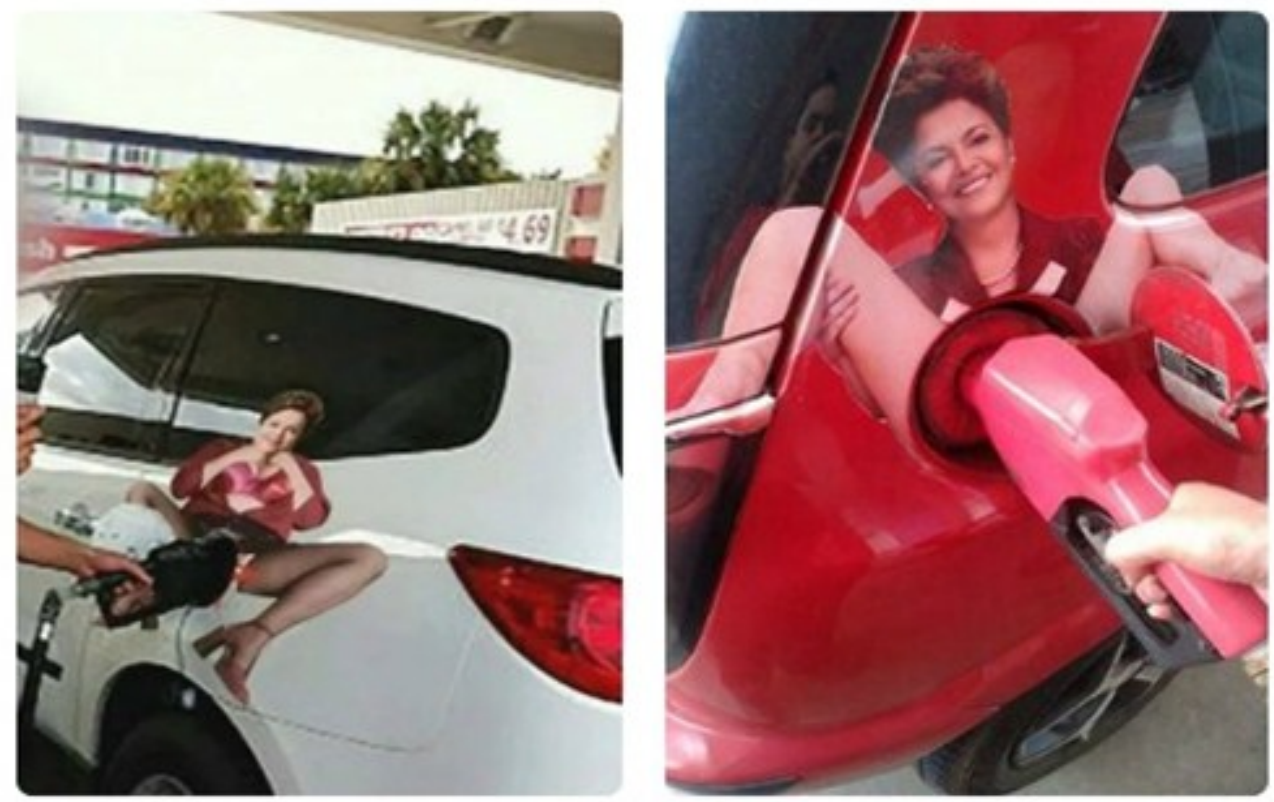

Fonte: Fotomontagem em circulação nas redes sociais.

3 UM POUCO DE TEORIA E ANÁLISE

A problemática da Cena da Enunciação, postulada por Dominique Maingueneau (2006 e 2013b), se inscreve na problemática mais ampla da heterogeneidade discursiva. Essa problemática, embora estivesse presente nas preocupações de Michel Pêcheux desde os seus primeiros escritos, ainda no final dos anos sessenta do século passado, inicialmente, a partir da noção-conceito de formação discursiva e, depois, a partir das noções de pré-construído e de interdiscurso, é com os trabalhos de Jean-Jacques Courtine, acerca do enunciado dividido, e de Jacqueline Authier-Revuz, sobre as heterogeneidades enunciativas, que a questão ganha uma discussão teórica mais densa.

É preciso considerar, todavia, que além de Pêcheux, Courtine e Authier-Revuz, outros autores, inscritos em paradigmas mais estritamente linguísticos, também se debruçaram sobre a questão da heterogeneidade. Benveniste, por exemplo, quando buscou tratar dos sentidos semântico e semiótico da linguagem, estava na verdade insistindo sobre o fato de que o enunciado extrai o seu sentido de diferentes fontes. No sentido semiótico, "o sentido que reenvia a ele mesmo é, de certa maneira, compreendido nele mesmo". Benveniste junta, a esse sentido semiótico, outro, o semântico, que "resulta do encaixamento e do ajustamento às circunstâncias e a colocação em relação dos signos uns com os outros" (1995, p.21). Os signos têm por consequência um sentido estável, mas também um sentido dinâmico; essa ideia encontra um prolongamento na distinção que estabelece Ducrot entre a significação (que produz as frases abstratas da língua) e o sentido (que produz os enunciados concretos).

Nos estudos enunciativos dos anos 50 e 60, o contexto de uma frase designa geralmente o contexto das frases vizinhas, que, se ligando a outras frases, formam um 
"discurso" (isto é, um texto). Por volta dos anos 70, os estudiosos da linguagem começam a levar em conta certos aspectos "extralinguísticos" do contexto. Assim, com "o aparelho formal da enunciação" [...], Benveniste se interessa pelas coordenadas espaço temporais e pessoais do contexto de enunciação. Em seguida, todavia, do mirante de uma semântica argumentativa, Ducrot centra o enunciado num contexto; o sentido é para Ducrot o produto de uma ligação entre um componente linguístico e o contexto de enunciação (DUCROT, 1984).

Ainda no âmbito dos estudos enunciativos, para Récanati, enquanto produto da enunciação o enunciado representa o traço de uma atividade linguageira que reenvia ao próprio enunciado. Para este autor, o enunciado coloca um representante $\mathrm{X}$ com um representante $\mathrm{Y}$, de maneira que "o representante $\mathrm{X}$ faz uma reflexão sobre ele mesmo e ao mesmo tempo, ele se representa" (RÉCANATI, 1979, p. 21). Esse caráter "autoreferencial" do enunciado representa igualmente a pragmática do discurso como a base da opacidade do enunciado.

Authier-Revuz, numa articulação entre o dialogismo bakhtiniano, a psicanálise lacaniana e a AD de base pêcheutiana, ampliando as discussões sobre as questões das heterogeneidades enunciativas, diferentemente de Récanati, se interessa pelo caso das não-coincidências do dizer, isto é, por tudo o que marca o não-um da comunicação: incompreensão, falta, mal-entendido, ambiguidade... Esses fenômenos são estudados, por exemplo, com a ajuda dos comentários metaenunciativos ou de conectores parafrásticos. Para Authier-Revuz, na linha de Culioli, que entende a comunicação enquanto um caso particular de mal-entendido, a ambiguidade e o mal-entendido não são acidentes da língua, que se caracterizariam pela transparência e ausência de parte da comunicação, mas como elementos constitutivos da própria língua.

Mesmo Michel Foucault, em A Arqueologia do Saber, ao asseverar que as formações discursivas se constituem a partir de enunciados, que existem segundo diferentes modalidades enunciativas, está na verdade tentando dar conta da questão da heterogeneidade discursiva. $\mathrm{O}$ rápido sobrevoo que propomos sobre diferentes autores nos mostra que, quer seja no âmbito dos estudos linguísticos e discursivos ou dos estudos foucaultianos acerca do discurso, cada um a seu modo, a questão da heterogeneidade sempre esteve centrada de uma maneira ou de outra na divisão entre texto e contexto.

Maingueneau, a partir da noção de cena de enunciação, mais especificamente com base no conceito de cenografia, busca colocar um ponto final na separação entre o texto e o contexto. Para Maingueneau, os textos organizam, gerenciam seus contextos. Estes últimos são pressupostos e validados pela enunciação. Não há, de um lado, um texto que seria o produto de outro lado, o contexto. A abordagem proposta por Maingueneau, acerca da cenografia, é sustentada pela hipótese radical segundo a qual os signos não podem ser saturados e não podem ser completados a partir de uma colocação direta em relação ao contexto, mas sim pelo fato de que esses signos reenviam ao contexto de maneira bastante particular.

Para dar conta analiticamente de nosso pequeno arquivo de textos anteriormente apresentado, asseveramos que é preciso refletir em termos de cena da enunciação, evitando, assim, algumas noções, tais como a de "situação de enunciação", que é de 
ordem estritamente linguística ou a de "situação de comunicação", que pode ser utilizada numa abordagem puramente sociológica, em que a atividade discursiva é descrita, de algum modo, do exterior. Além disso, segundo Maingueneau, o termo "cena" tem a vantagem de poder referir, ao mesmo tempo, a um quadro ("a cena representa...") e a um processo ("ao longo da cena", "uma cena de esgrima, de desfile militar"...). Enfim, ela permite realçar a importância do trabalho a que se dedicam permanentemente os participantes de um gênero de discurso: o de colocarem-se [ou serem colocados] em cena.

No entendimento de Maingueneau (2013, p. 80) "a concepção clássica de gênero é estruturada pela hierarquia de constituintes da cena de enunciação (Cena Englobante > Cena Genérica > Cenografia); a cena genérica serve de pivô e o hipergênero ${ }^{6}$ interpreta um papel marginal. No caso da web, ao contrário, as coerções da cena genérica são fracas. Os sites, qualquer que seja seu conteúdo, estão submetidos a um conjunto de coerções técnicas, e esta homogeneização é reforçada pela necessidade de poder circular por hiperligações de um site a outro. Em razão dessa "ligação" de diferentes gêneros, é doravante a cenografia que interpreta um papel-chave: a principal fonte é a encenação da comunicação, que mobiliza massivamente as fontes propriamente verbais, multimodais (imagem fixa, em movimento, som) e as operações hipertextuais.

Todo discurso, por sua própria constituição, reivindica a adesão ao seu universo instituindo a cenografia que o legitima. Evidentemente, tal cenografia é imposta desde o início, mas é por meio da enunciação que essa cenografia imposta pode ser legitimada. A cenografia é desse modo, ao mesmo tempo, o que engendra o discurso, e o que é engendrado por ele; ela legitima um enunciado verbal ou imagético que, por sua vez, deve legitimá-la. Essa cenografia que possibilita o discurso é precisamente a cenografia necessária para enunciar como convém neste ou naquele gênero de discurso.

As cenografias geralmente se apoiam em cenas de fala já validadas na cultura: situações de comunicação caracterizadas pelos gêneros, mas também por eventos únicos de fala, por exemplo, o slogan de campanha de Barack Obama: "Yes, we can" nas eleições presidenciais de 2008. Esse slogan de Obama se apoiou no slogan da United Farm Workers já validado na sociedade norte-americana: "Si, se pude". Nesse caso, "validado" não quer dizer "valorizado", mas já instalado na memória coletiva, no universo de saber e de valores do público (MAINGUENEAU, 2006).

As três primeiras fotografias mobilizadas para a análise se inscrevem numa mesma cena englobante: discurso jornalístico, e numa mesma cena genérica: comunicação política. No entanto, essas imagens, embora façam referência ao mesmo ator político, Dilma Rousseff, importam para si diferentes cenografias, inscritas inicialmente em outras cenas genéricas. Já a quarta fotografia analisada pertence à cena englobante dos adesivos misóginos colados em carros e à cena genérica da fotomontagem derrisória.

\footnotetext{
${ }^{6}$ Segundo Dominique Maingueneau (2013b, p. 80) a web transformou profundamente as condições de comunicação, engendrando mudanças no gênero e na própria noção de textualidade. Não se trata apenas de um novo espaço de apresentação e de circulação dos gêneros. Se antes, em cenas genéricas tradicionais, como por exemplo o jornal impresso, o hipergênero, isto é, o amálgama de diferentes gêneros em um único dispositivo ocupava um lugar central, com a irrupção da web, o hipergênero cede espaço para as mais distintas relações intercenográficas.
} 
A primeira importa a cenografia de uma disputa de esgrima em que um dos combatentes, no caso Dilma Rousseff, ao ser atacada pelas costas, é atravessada pela espada do seu oponente. Nessa cenografia, apesar de ser atacada pelas costas, a fotografia parece sugerir certa resignação do ator político Dilma, visto que esta última está com o corpo levemente arqueado e com o rosto sugerindo uma expressão de dor. A cenografia em questão retoma interdiscursivamente um discurso latente na nossa sociedade de que o PMDB, segundo maior partido da base aliada de sustentação do governo Dilma, sistematicamente ao votar em desacordo com as orientações do governo tem tentado sorrateiramente golpear pelas costas a atual presidente. Trata-se de uma retomada interdiscursiva que no mesmo processo valida a própria cenografia.

A segunda importa uma cenografia bélica em que um tanque de guerra aponta o seu canhão para um dos inimigos, no caso o ator Dilma Rousseff. A fotografia sugere, por um lado, que o ator político Dilma Rousseff parece aceitar passivamente o seu fim, pois não há nenhum esboço de reação e, por outro, parece sugerir que embora estejam presentes muitas autoridades na comemoração do dia da independência, a presidente Dilma é o único alvo a ser abatido. Esta cenografia traz interdiscursivamente à tona as denúncias de corrupção na Petrobrás, investigadas pela Polícia Federal, a partir de 17 de março de 2014. Essa ação foi designada pela Polícia Federal como "Operação Lava a Jato". São essas denúncias retomadas interdiscursivamente que validam a cenografia bélica presente na fotografia em questão.

A terceira, por sua vez, coloca o ator Dilma Rousseff com as mãos cobrindo o rosto, importando uma cena em que um sujeito está totalmente desesperado e em profunda angústia. A fotografia sugere que o ator político Dilma Rousseff definitivamente sucumbiu ante os ataques dos adversários. Esse estado desesperador sugerido pela fotografia do ator Dilma lembra lateralmente o quadro do pintor expressionista Edward Much, pintado em 1893, O Grito. Esta cenografia, diferentemente das anteriores, não retoma interdicursivamente um discurso já sedimentado na nossa sociedade, ela na verdade constrói uma espécie de cenário futuro para que esse discurso se efetive.

A quarta e última imagem importa a cenografia de uma personagem feminina que aparece numa posição na qual está prestes a ser penetrada sexualmente. Esse tipo de cenografia geralmente circula em revistas pornográficas destinadas ao público masculino. Diferentemente das outras três imagens, esta última, por se constituir em um adesivo misógino, que inicialmente circulou nos automóveis e depois nas redes sociais, colado especificamente no tanque de gasolina, constrói um tipo particular de cenografia. Trata-se de uma espécie de cenografia interativa em que toda vez que o carro é abastecido, a presidente é supostamente penetrada pela mangueira da bomba de gasolina. Trata-se de uma espécie de catarse às avessas da população brasileira em relação à gestão da presidente Dilma. Todavia, esse tipo de crítica ultrapassa os limites da razão e se aloja na bestialidade de um estupro. Esta cenografia retoma interdiscursivamente o ódio manifestado por parte da população brasileira em relação ao ex-presidente Lula e à atual presidente Dilma. É essa retomada interdiscursiva do discurso do ódio que legitima a cenografia em questão. 
As diferentes cenografias, conforme já enunciado, colocam o ator político Dilma Rousseff numa situação extremamente disfórica. Cada uma delas refrata um dos momentos de tensão política pelo qual o governo Dilma vem passando desde a sua posse em janeiro de 2011: pressão do PMDB por mais cargos no primeiro e no segundo escalão do governo; denúncias de corrupção na Petrobrás; manifestações pelo impeachment da presidente e protestos contra o aumento dos combustíveis. Com efeito, essas fotografias intercenograficamente produzem, por um lado, uma espécie de passagem gradual de um estágio brando para outro intenso da tensão política existente no país e, por outro, colocam o ator político Dilma Rousseff pouco a pouco resignadamente sucumbindo aos ataques dos adversários, chegando um momento de total angústia e desespero.

No caso em análise, as cenografias instauradas nas quatro fotografias, ao mostrar o ator político Dilma sendo atacado e sucumbindo a esse ataque, se, por um lado, subvertem o que seria a cenografia endógena do gênero comunicação política, por outro, buscam legitimar o discurso de que o país vem gradativamente mergulhando numa profunda crise política desde a posse do primeiro mandato de Dilma em janeiro de 2011. Ademais, sobretudo a última fotografia mostra simbolicamente que uma parcela significativa da população brasileira, pouco afeita ao debate democrático, se vale de qualquer expediente, mesmo de um estupro, para atingir seus objetivos.

\section{UM BREVE EFEITO DE FIM}

As quatro fotografias a partir da importação de diferentes cenografias inicialmente inscritas em outras cenas genéricas, constituindo distintas relações intercenográficas, evidenciando que a imagem é engendrada por uma (des)ordem discursiva, parecem legitimar, por um lado, o sentido de que gradativamente o governo Dilma Rousseff caminha em direção à "beira da falésia " ", e, por outro, que ódio de parte da população da brasileira em relação ao ex-presidente Lula e a Dilma se aloja simbolicamente numa tentativa de estupro da atual presidente, ou seja, constroem uma narrativa na qual o governo caminha para o campo da inquietude e, sobretudo, da incerteza, e que é preciso, por conta desse estado de incerteza, retirar a qualquer custo o governo que foi eleito democraticamente pela maioria da população brasileira em outubro passado para exercer o seu mandato. Essa narrativa constrói um percurso deôntico de interpretação para os leitores que ratifica o estado de inquietude, de incerteza e de ódio, contribuindo bastante para que os brasileiros, num processo de completo esvaziamento do político na política, deixem de confrontar propostas de governo e passem a torcer ou a odiar, como torcedores de futebol mesmo, para político $\mathrm{X}$ ou $\mathrm{Y}^{8}$.

Os quatro dados brevemente analisados nos mostram que, para dar conta da comunicação política que circula na web, é preciso assumir o postulado de que a

\footnotetext{
${ }^{7}$ Expressão tomada de empréstimo do título do livro do historiador francês Roger Chartier "À beira da falésia: a história entre certezas e inquietude", publicada pela Editora da Universidade Federal do Rio Grande do Sul - UFRGS em 2002.

${ }^{8}$ Agradeço ao colega Wander Emediato, da UFMG, por essa importante contribuição ao meu trabalho.
} 
imagem é engendrada por diferentes (des)ordens discursivas e também avançar os postulados de Maingueneau (2006), acerca das noções de cena englobante, genérica e cenografia, do contrário corremos o risco de perder a possibilidade de compreender o mecanismo que engendra as relações intercenográficas que dão vida e legitimidade aos gêneros. Ao pensarmos nas relações intercenográficas não estamos propondo um novo nome para as constitutivas relações interdiscursivas, que todo discurso mantém com outro(s) discurso(s); estamos, na verdade, buscando compreender o processo discursivo pelo qual uma cena genérica, para se constituir e, sobretudo, se legitimar, a partir de determinados princípios (linguísticos, históricos, culturais, conjunturais, institucionais, ideológicos...), importa para si cenografias, que inicialmente estavam aninhadas em outros textos e que faz delas o fundamento de sua organicidade e sua legitimação.

\section{REFERÊNCIAS}

AUTHIER-REVUZ, J. Entre a transparência e a opacidade. Porto Alegre: Edipucrs, 2004.

ANGERMULLER, J. Analyse du discours poststructuraliste: les voix du sujet dans le langage chez Lacan, Althusser, Foucault, Derrida, Sollers. Paris. Éditions Lambert-Lucas, 2013.

BAKHTIN, M. Os gêneros do discurso. In:____. Estética da Criação Verbal. Trad. de Maria Hermínia Galvão G. Pereira. São Paulo: Martins Fontes, 2003. p. 261-306.

BENVENISTE, E. Problemas de Linguística Geral I. Campinas, SP: Editora da UNICAMP, 1995.

CHARAUDEAU, P.; MAINGUENEAU, D. Dicionário de Análise do Discurso. Coord. Trad. Fabiana Komesu. 2. ed. São Paulo: Contexto, 2006.

CHARTIER, R. À beira da falésia: a história entre certezas e inquietude. Porto Alegre, RS: Editora da Universidade Federal do Rio Grande do Sul - UFRGS, 2002.

DAVALLON, J. A imagem, uma arte de memória. In: ACHARD, P. et al. Papel da memória. Trad. e intr. de José Horta Nunes. Campinas, SP: Pontes, 1999.

DUCROT, O. O dizer e o dito. Campinas, SP: Ed. da Unicamp, 1995.

FOUCAULT, M. A ordem do discurso: aula inaugural no Collège de France, pronunciada em 2 de dezembro de 1970. São Paulo, SP: Loyola, 1999.

(Org.). Eu, Pierre Rivière, que degolei minha mãe, minha irmã e meu irmão: um caso de parricídio do século XIX. Trad. Denize Lezande Almeida. 2. ed. Rio de Janeiro: Graal, 1981.

MAINGUENEAU, D. Cenas da enunciação. Curitiba: Criar Edições, 2006.

. Análise de textos de comunicação. São Paulo: Cortez, 2013a.

Genres de discours et web: existe-t-il des genres web? In: BARATS, C. Manuel d'analyse du web. Paris: Armand Colin, 2013b.

. Discurso e análise do discurso. Trad. de Sírio Possenti. São Paulo, SP: Parábola Editorial, 2015.

RÉCANATI, F. La transparence et l'énonciation: pour introduire à la pragmatique. Paris: Le Seuil, 1979.

Recebido em: 17/07/15. Aprovado em: 02/11/15

Title: The (dis)order of the Image in Brazilian Political Communication: Analytical Possibilities from Discursive Theorical-Notion of Relations of Inter-Scenography

Author: Roberto Leiser Baronas

Abstract: In this text, that the image while "an operator of social memory within our culture" like any other discourse, is engendered by a discursive order as well as by a discursive disorder and that these discursive (dis)orders occur in generic scenes quite 
marked institutionally. By assuming that the postulate from different discursive (dis)orders construct not only verbal, but also the image, our specific question in this paper is how, in a discursive way, can we apprehend this (dis)order image in the digital political communication? What conceptual tools could we mobilize to understand the (dis)order of the image in political communication? Those questions we are supporting theoretically and methodologically on Dominique Maingueneau's propositions (2006 and 2013b), more specifically in the conceptual triad encompassing scene, generic scene and scenography, making the last notion creak while discursive relations of inter-scenography and, for this paper, it was collected a small set of images, specifically photographs, that circulated in Brazilian's digital media and social networks between the years 2011-2015, as a political communication about the political actor Dilma Rousseff.

Keywords: Discourse. Image. Enunciative scene. Relations of inter-scenography.

Título: El (des)orden de la imagen en la comunicación politica brasileña: posibilidades analiticas desde la noción discursiva de relaciones intercenográficas

Autor: Roberto Leiser Baronas

Resumen: En este artículo se postula que la imagen, mientras un "operador de la memoria social dentro de nuestra cultura", como cualquier otro discurso, es engendrada por un orden y por un desorden discursivo, y que esas (des)ordenes discursivas ocurren en escenas genéricas bastante marcadas institucionalmente. Por presumir el postulado de que diferentes (des)ordenes discursivas engendran no solo lo que es verbal, pero la imagen, la cuestión específica en este artigo es cómo podemos aprender discursivamente ese (des)orden de la imagen en la comunicación política digital. ¿Cuáles herramientas conceptuales podríamos movilizar para entender el (des)orden de la imagen en la comunicación política? El texto se basa teórico-metodológicamente en las proposiciones de Dominique Maingueneau (2006 y 2013b), bajo la luz de la tríade conceptual escena englobante, escena genérica y escenografia, haciendo esta última noción rechinar, mientras la relación discursiva inter-escenográfica, y moviliza un pequeño conjunto de imágenes, más especialmente fotografías, que circularan en el medio digital y en las redes sociales brasileñas entre los años de 2011 y 2015, mientras comunicación politica, sobre el actor político Dilma Rousseff.

Palabras-clave: Discurso. Imagen. Escena da enunciación. Relaciones interescenográficas. 